\title{
Small-Molecule Donor/Polymer Acceptor Type Organic Solar Cells: Effect of Terminal Groups of Small-Molecule Donors
}

\author{
Junhui Miao a,b \\ Bin Meng*a \\ Jun Liu*a (i) \\ Lixiang Wang ${ }^{a}$ \\ a State Key Laboratory of Polymer Physics and Chemistry, Changchun Institute of Applied \\ Chemistry, Chinese Academy of Sciences, \\ Changchun, People's Republic of China \\ mengbin@ciac.ac.cn; liujun@ciac.ac.cn \\ University of Science and Technology of China, \\ Hefei, People's Republic of China
}

Received: 29.09.2019

Accepted after revision: 29.10.2019

DOI: 10.1055/s-0039-3401017; Art ID: om-19-0014-oa

License terms: (C) $(\bigoplus$

(๑) 2019. The Author(s). This is an open access article published by Thieme under the terms of the Creative Commons Attribution-NonDerivative-NonCommercial-License, permitting copying and reproduction so long as the original work is given appropriate credit. Contents may not be used for commercial purposes, or adapted, remixed, transformed or built upon. (https://creativecommons.org/licenses/by-nc-nd/4.0/).

Abstract Small-molecule donor/polymer acceptor type $\left(\mathrm{M}_{\mathrm{D}} / \mathrm{P}_{\mathrm{A}}\right.$-type $)$ organic solar cells (OSCs) have the great advantage of superior thermal stability. However, very few small molecular donors can match polymer acceptors, leading to low power conversion efficiency (PCE) of $\mathrm{M}_{\mathrm{D}} / \mathrm{P}_{\mathrm{A}^{-}}$ type OSCs. In this work, we studied the effect of terminal groups of small molecular donors on the optoelectronic properties and OSC device performance of $\mathrm{M}_{\mathrm{D}} / \mathrm{P}_{\mathrm{A}}$-type OSCs. We select a benzodithiophene unit bearing carbazolyl substituents as the core, terthiophene as the bridging unit, and electron-withdrawing methyl 2-cyanoacetate, 3ethylrhodanine, and $2 \mathrm{H}$-indene-1,3-dione as the terminal groups to develop three small-molecule donors. With the increase of the electronwithdrawing capability of the terminal groups, the small molecular donors exhibit redshifted absorption spectra and downshifted LUMO levels. Among the three small-molecule donors, the one with 3ethylrhodanine terminal group exhibits the best photovoltaic performance with the PCE of $8.0 \%$ in $\mathrm{M}_{\mathrm{D}} / \mathrm{P}_{\mathrm{A}}$-type OSCs. This work provides important guidelines for the design of small-molecule donors for $\mathrm{M}_{\mathrm{D}} / \mathrm{P}_{\mathrm{A}^{-}}$ type OSC applications.

Key words Small-molecule donor, organic solar cells, optoelectronic properties

\section{Introduction}

Organic solar cells (OSCs) have attracted great attention due to their advantages of lightweight, flexibility and solution processability at low cost. ${ }^{1-5}$ In the last 10 years, the power conversion efficiencies (PCEs) of OSCs have been improved over $16 \%$, which is close to the key point for commercial applications and thus the device stability
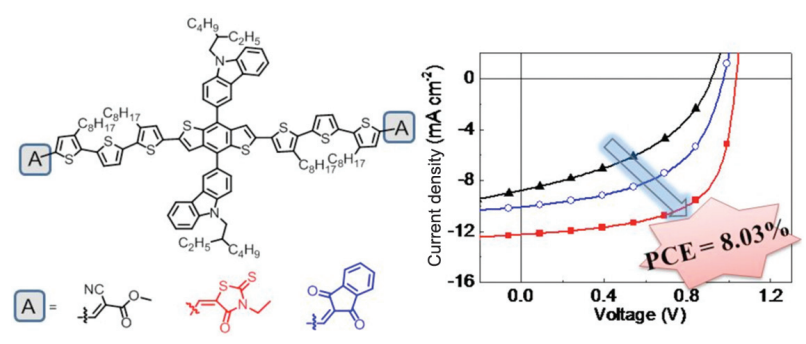

should be paid attention. ${ }^{6-11}$ Both organic small molecules and polymers can be used as electron donors/acceptors for OSC applications. ${ }^{12-34}$ Among them, the small-molecule donor and polymer acceptor type $\left(\mathrm{M}_{\mathrm{D}} / \mathrm{P}_{\mathrm{A}}\right.$-type $)$ OSCs exhibit superior active layer morphology stability under thermal treatment, implying great potential for practical applications. ${ }^{35-38}$ However, the PCE of the $\mathrm{M}_{\mathrm{D}} / \mathrm{P}_{\mathrm{A}}$-type OSCs lags far behind that of the other types of OSCs. Most of the $\mathrm{M}_{\mathrm{D}} / \mathrm{P}_{\mathrm{A}}$-type OSCs show poor photovoltaic performances (PCE 5\%). ${ }^{39-43}$ Most importantly, the relationship between the chemical structure and OSC device performance in $\mathrm{M}_{\mathrm{D}} / \mathrm{P}_{\mathrm{A}}$-type OSCs has not been established.

Traditional small-molecule donors possess small steric hindrance groups at the core, and usually exhibit severe aggregation in the solid state, which would lead to large-scale phase separation when blending with polymer acceptors and consequently showing poor performances of OSCs. ${ }^{44-49}$ Recently, we have developed a small-molecule donor with large steric hindrance at the core to inhibit the aggregation of backbones, and greatly improved the performance of $\mathrm{M}_{\mathrm{D}} / \mathrm{P}_{\mathrm{A}^{-}}$ type OSCs. ${ }^{50}$ The preliminary result motivates us to investigate the structure-performance relationship of molecules and develop efficient small-molecule donors for $\mathrm{M}_{\mathrm{D}} / \mathrm{P}_{\mathrm{A}}$-type OSCs.

In this study, we develop three small-molecule donors, DC3TBDTC, DR3TBDTC and DI3TBDTC, with a benzodithiophene unit bearing bulky carbazolyl substituents as the core unit, terthiophene as the bridging unit, and electronwithdrawing methyl 2-cyanoacetate, 3-ethylrhodanine and $2 \mathrm{H}$-indene-1,3-dione as the terminal groups. The chemical structures of these small-molecule donors are shown in Scheme 1a. The electron-withdrawing terminal groups obviously affect the absorption spectra and LUMO energy levels of the small molecular donors, and consequently significantly affect the photovoltaic performance. ${ }^{51-55}$ The one with the 3-ethylrhodanine terminal group exhibits the best photovoltaic performance with the PCE of $8.0 \%$ in $M_{D} / P_{A^{-}}$ type OSCs. This work provides important guidelines for the design of small-molecule donors for $\mathrm{M}_{\mathrm{D}} / \mathrm{P}_{\mathrm{A}}$-type $\mathrm{OSC}$ applications. 

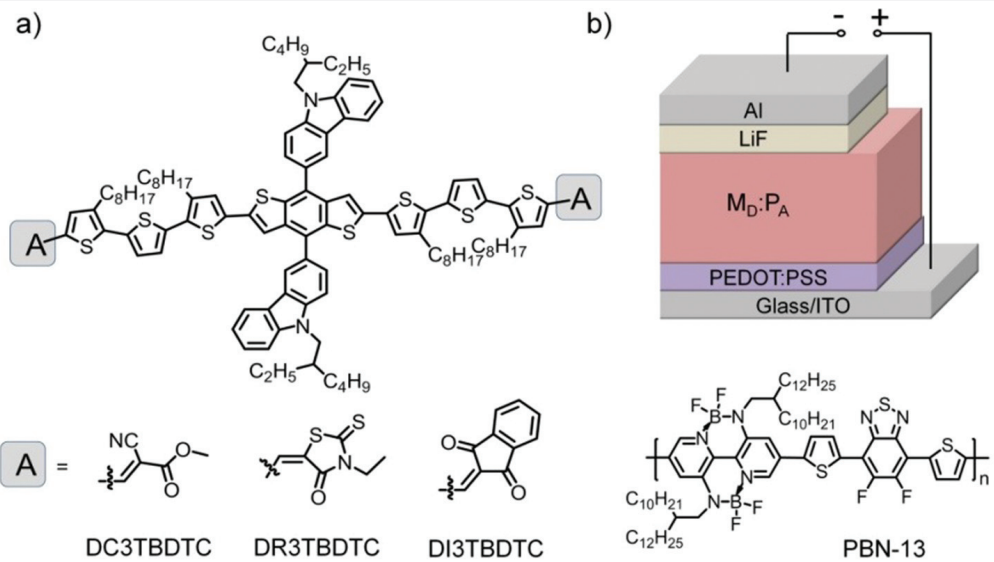

Scheme 1 (a) Chemical structures of small-molecule donors DC3TBDTC, DR3TBDTC and DI3TBDTC. (b) The $M_{D} / P_{A^{-}}$type OSC device structure and chemical structure of polymer acceptor, PBN-13.

\section{Results and Discussions}

The synthetic routes of small-molecule donors are illustrated in Supplementary Figure S1. The chemical structures of small-molecule donors are characterized by ${ }^{1} \mathrm{H}$ NMR, ${ }^{13} \mathrm{C}$ NMR and elemental analysis (Supplementary Figures S2 and S3). According to thermogravimetric analysis (TGA), all of these molecules exhibit good thermal stability with decomposition temperatures $\left(T_{\mathrm{d}}, 5 \%\right.$ weight loss) of 375 , 406 and $322^{\circ} \mathrm{C}$ under a nitrogen atmosphere for DC3TBDTC, DR3TBDTC and DI3TBDTC, respectively (Supplementary Figure S4a and Table 1). According to differential scanning calorimetry (DSC) measurement, DC3TBDTC, DR3TBDTC and DI3TBDTC all exhibit obvious melting peaks and crystallization peaks, suggesting that these molecules have good crystallinity (Supplementary Figure S4b).

Theoretical calculations by density functional theory (DFT) at the B3LYP/6-31G(d,p) level were performed to investigate the influence of the terminal groups on the molecular configuration and the electrical structures of DC3TBDTC, DR3TBDTC and DI3TBDTC. The optimized molecular geometries and HOMO/LUMO distributions are shown in Supplementary Figure S5. All these molecules exhibit nearly planar conjugated backbones with the dihedral angles between the carbazolyl substituents and the benzodithiophene core of $57^{\circ}-58^{\circ}$. So, the bulky substituents can be served as steric hindrance groups to prevent molecular aggregation. The three molecules show similar HOMO/LUMO distributions. The HOMOs are mainly focused on the center of molecular skeletons, while the LUMOs are mainly distributed on the two sides, implying that the terminal groups contribute more on the LUMOs.

The HOMO/LUMO energy levels of DC3TBDTC, DR3TBDTC and DI3TBDTC were estimated by cyclic voltammetry (CV) measurement. The cyclic voltammograms are shown in Figure 1a and the data are listed in Table 1. The HOMO/LUMO energy levels of DC3TBDTC, DR3TBDTC and DI3TBDTC are estimated to be $-5.23 /-3.26,-5.18 /-3.09$ and $-5.19 /-3.40 \mathrm{eV}$, respectively. The three molecules exhibit similar HOMO energy levels and quite different LUMO energy levels, indicating that the terminal groups of these molecules greatly affect the LUMOs. The CV results are consistent with the DFT-calculated results. Due to the strong electron-withdrawing capacity of $2 \mathrm{H}$-indene-1,3-dione, DI3TBDTC shows the lowest LUMO energy level, which further leads to the narrowest bandgap of $1.79 \mathrm{eV}$. Figure $1 \mathrm{~b}$ shows the energy-level alignment of the small-molecule donors and a commonly used boron-nitrogen coordination bond ( $\mathrm{B} \leftarrow \mathrm{N}$ ) polymer acceptor, $\mathrm{PBN}-13$. The HOMO/LUMO energy levels of these molecules are much higher than that of PBN-13, implying that charge transfer can occur and that these molecules should be suitable for electron donors.

The absorption spectra of DC3TBDTC, DR3TBDTC, and DI3TBDTC in chlorobenzene solution and in thin films are

Table 1 The optical, electrochemical and thermal properties of DC3TBDTC, DR3TBDTC and DI3TBDTC

\begin{tabular}{lllllllllllll}
\hline Donors & $E_{\text {onset }}{ }^{\text {ox }}(\mathrm{V})$ & $E_{\text {onset }}{ }^{\text {red }}(\mathrm{V})$ & $E_{\text {Hомо }}(\mathrm{eV})$ & $E_{\text {LUmo }}(\mathrm{eV})$ & $E_{\mathrm{g}}(\mathrm{eV})$ & $\lambda_{\max }{ }^{\text {sol }}(\mathrm{nm})$ & $\lambda_{\max }{ }^{\text {film }}(\mathrm{nm})$ & $\varepsilon^{\text {film }}\left(10^{4} \mathrm{~cm}^{-1}\right)$ & $E_{\mathrm{g}}{ }^{\mathrm{opt}}(\mathrm{eV})$ & $T_{\mathrm{d}}\left({ }^{\circ} \mathrm{C}\right)$ & $T_{\mathrm{m}}\left({ }^{\circ} \mathrm{C}\right)$ & $T_{\mathrm{c}}\left({ }^{\circ} \mathrm{C}\right)$ \\
\hline DC3TBDTC & 0.43 & -1.64 & -5.23 & -3.16 & 2.07 & 501 & 558 & 5.2 & 1.85 & 375 & 227 & 189 \\
DR3TBDTC & 0.38 & -1.71 & -5.18 & -3.09 & 2.09 & 517 & 578 & 6.1 & 1.79 & 406 & 257 & 219 \\
DI3TBDTC & 0.38 & -1.40 & -5.19 & -3.40 & 1.79 & 538 & 600 & 6.4 & 1.72 & 322 & 188 & 145 \\
\hline
\end{tabular}


a)

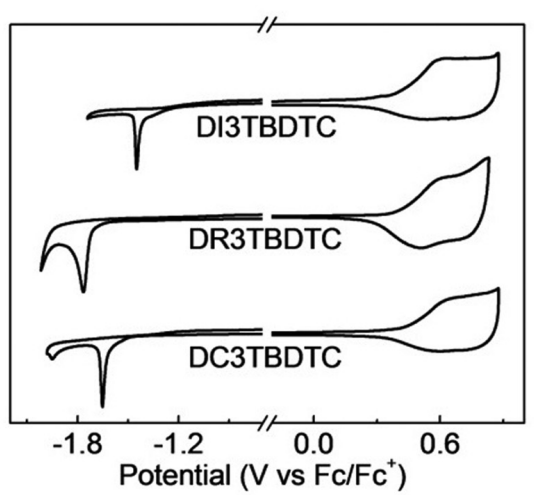

b)

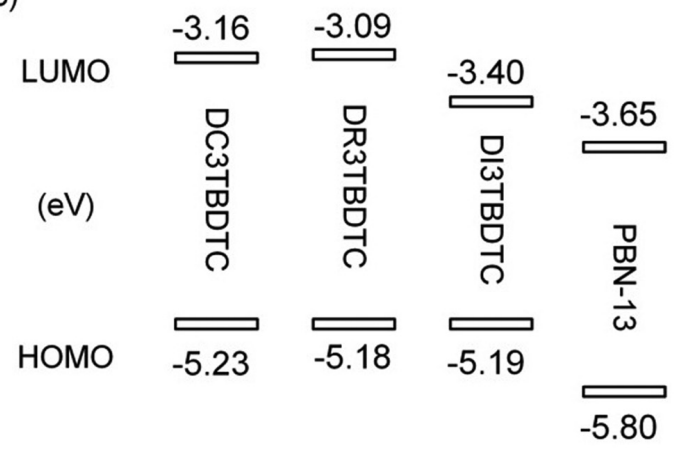

Figure 1 (a) Cyclic voltammograms of DC3TBDTC, DR3TBDTC and DI3TBDTC. (b) Energy level alignment for DC3TBDTC, DR3TBDTC, DI3TBDTC and PBN-13.

presented in Figure 2. In solution, all of these molecules exhibit two absorption bands in the visible region with the maximum absorption peak at 501, 517 and $538 \mathrm{~nm}$ for DC3TBDTC, DR3TBDTC and DI3TBDTC, respectively. From solution to the thin film, the absorption bands of these molecules become much broader and the absorption edges are redshifted by 74, 91 and $93 \mathrm{~nm}$ for DC3TBDTC, DR3TBDTC and DI3TBDTC, respectively. The significant redshift suggests that strong intermolecular interaction is present in the solid state of these molecules. Moreover, the broad multiple absorption bands in the visible region indicate strong sunlight harvesting abilities of these molecules, which are favorable for OSC applications. According to the onset absorption, the optical band gaps $\left(E_{\mathrm{g}}\right)$ of DC3TBDTC, DR3TBDTC and DI3TBDTC are estimated to be $1.85,1.79$ and $1.72 \mathrm{eV}$, respectively.

To investigate the photovoltaic performance of these molecules as electron donors for $\mathrm{M}_{\mathrm{D}} / \mathrm{P}_{\mathrm{A}}$-type OSCs, we selected $\mathrm{PBN}-13$ as the polymer acceptor to fabricate
OSC devices with a conventional device structure of ITO/ poly(3,4-ethylenedioxythiophene):poly(styrenesulfonate) (PEDOT:PSS)/DC3TBDTC or DR3TBDTC or DI3TBDTC:PBN13/LiF/Al (Figure 1b). The current density-voltage $(J-V)$ curves of the devices are shown in Figure $3 a$ and the detailed photovoltaic parameters are listed in Table 2. The OSC device based on DC3TBDTC exhibits a PCE of 5.20\%, with an opencircuit voltage $\left(V_{\mathrm{OC}}\right)$ of $0.97 \mathrm{~V}$, a short-circuit current density $\left(J_{\mathrm{SC}}\right)$ of $10.10 \mathrm{~mA} \mathrm{~cm}^{-2}$ and a fill factor $(\mathrm{FF})$ of 0.52 . The OSC device based on DR3TBDTC shows a PCE of $8.03 \%$, with a $V_{\text {OC }}$ of $1.03 \mathrm{~V}$, a $J_{\mathrm{SC}}$ of $12.27 \mathrm{~mA} \mathrm{~cm}^{-2}$ and an FF of 0.64 . While the device of DI3TBDTC shows a $V_{\mathrm{OC}}$ of $0.92 \mathrm{~V}$, a $J_{\mathrm{SC}}$ of $8.79 \mathrm{~mA} \mathrm{~cm}^{-2}$ and an FF of 0.42 , corresponding to a PCE of $3.37 \%$. The introduction of 3-ethylrhodanine terminal groups of DR3TBDTC gave the best PCE of $8.03 \%$, which is among the highest values reported for $\mathrm{M}_{\mathrm{D}} / \mathrm{P}_{\mathrm{A}}$-type OSCs. Compared with DR3TBDTC, DC3TBDTC and DI3TBDTC showed inferior $J_{S C}$ values, the former is, may be, ascribed to the low absorption coefficient and the latter is ascribed to the inadequate charge
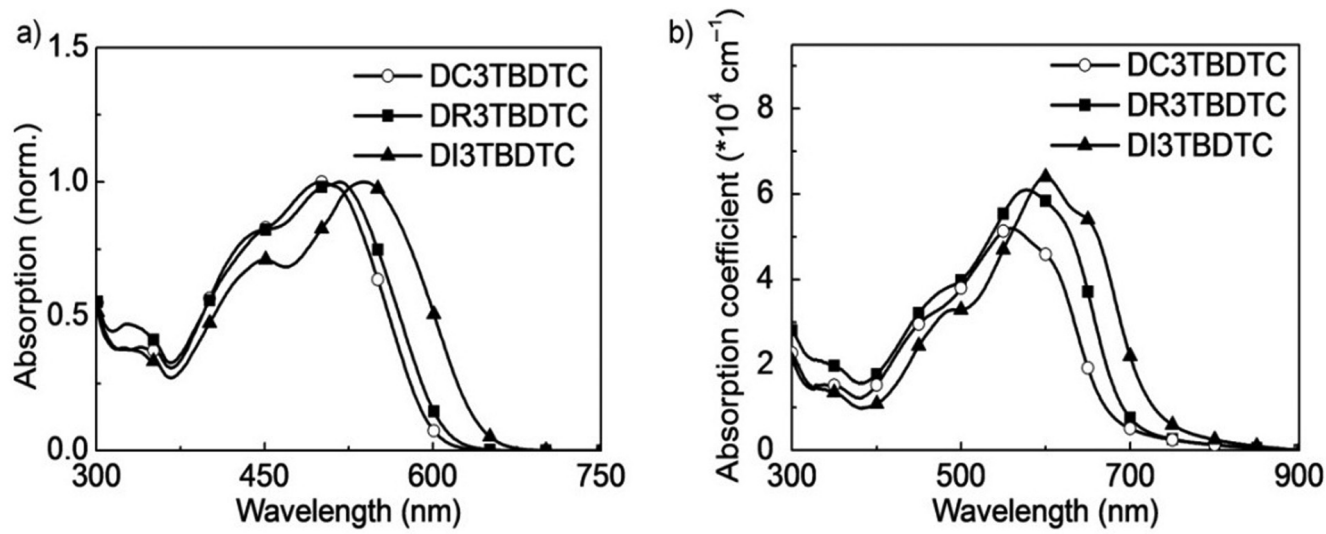

Figure 2 UV-vis absorption spectra of DC3TBDTC, DR3TBDTC and DI3TBDTC: (a) in solution and (b) in film. 

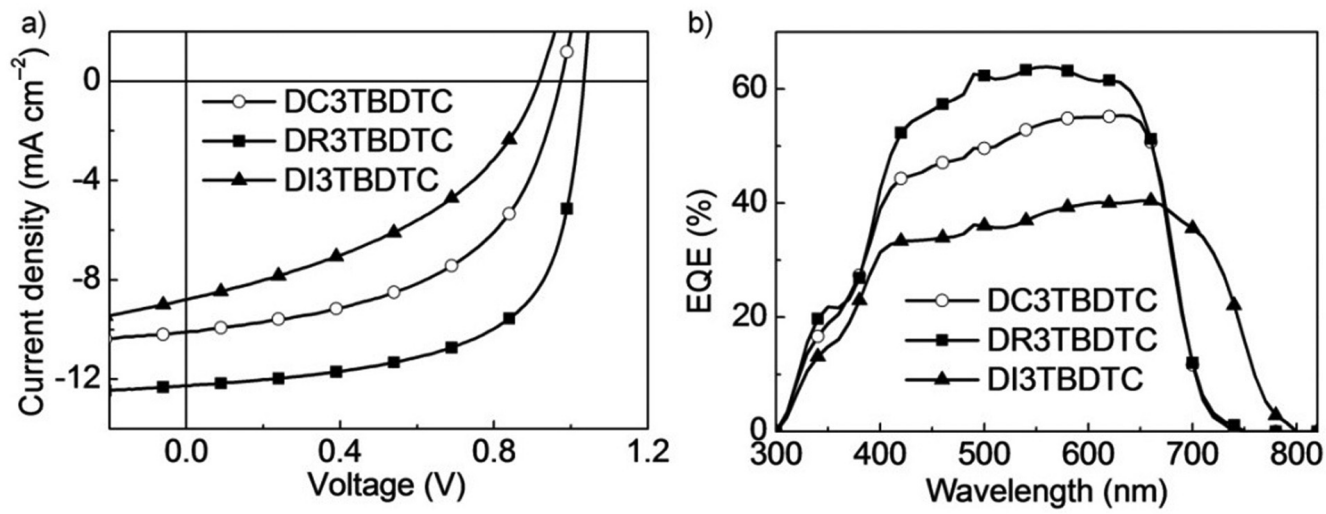

Figure 3 (a) J-V plots and (b) EQE spectra of the OSC devices based on DC3TBDTC, DR3TBDTC and DI3TBDTC under the illumination of AM 1.5 G, $100 \mathrm{~mW} \mathrm{~cm}^{-2}$.

separation in OSC devices (vide infra). The external quantum efficiency (EQE) curves of these devices are shown in Figure $3 \mathrm{~b}$. Compared to DC3TBDTC and DR3TBDTC, the DI3TBDTC-based device shows a broader photoresponse range due to the redshifted absorption spectrum of DI3TBDTC. The $J_{\mathrm{SC}}$ values estimated by the integration of the EQE spectra are consistent with the $J_{\mathrm{SC}}$ data from the $J-V$ measurement (Table 2 ).

To gain further insights into the OSC devices, the surface morphology of the DC3TBDTC:PBN-13, DR3TBDTC:PBN-13 and DI3TBDTC:PBN-13 blends were investigated by atomic force microscopy (AFM). The height and phase images of these blends are shown in Figure 4. All of the blend films show a little rough surface with similar root mean square (RMS) roughness of 1.95, 2.28 and $2.40 \mathrm{~nm}$ for DC3TBDTC: PBN-13, DR3TBDTC:PBN-13 and DI3TBDTC:PBN-13, respectively. The phase separation scale size is also similar according to the phase images (Figure $4 \mathrm{~b}, \mathrm{~d}, \mathrm{f}$ ). The AFM result suggests that the terminal groups of these molecules have little impact on the donor/acceptor blend morphology.

Photoluminescence (PL) spectra were measured to investigate the exciton dissociation behavior in the blends. Figure 5 shows the PL spectra of the pure donor films and the blend films excited at $560 \mathrm{~nm}$. The pure DC3TBDTC and DR3TBDTC films show similar PL emission bands in the range of $630-820 \mathrm{~nm}$. When blending with a polymer acceptor, their corresponding emissions are almost quenched by over $90 \%$, suggesting effective electron transfer from DC3TBDTC or DR3TBDTC to PBN-13. However, the PL spectrum is only quenched by $74 \%$ for the blend film based on DI3TBDTC, implying that electron transfer from DI3TBDTC to PBN-13 is partially suppressed. As the three blends have similar phase separation scale sizes, the poor PL quenching efficiency of DI3TBDTC:PBN-13 may be ascribed to the smaller LUMO energy offset of $0.25 \mathrm{eV}$. The inadequate charge separation in the DI3TBDTC:PBN-13 blend may be one of the reasons for its inferior device performance.

The charge carrier mobilities of these blend films were measured using the space-charge limited current (SCLC) method with the hole-only device structure of ITO/PEDOT:PSS/active layer/ $/ \mathrm{MoO}_{3} / \mathrm{Al}$ and the electron-only device structure of ITO/PEIE/active layer/Ca/Al, respectively. The SCLC curves are shown in Supplementary Figure S6. The hole/electron mobilities $\left(\mu_{\mathrm{h}} / \mu_{\mathrm{e}}\right)$ are estimated to be $1.20 \times 10^{-4} / 2.10 \times 10^{-4} \mathrm{~cm}^{-2} \mathrm{~V}^{-1} \mathrm{~s}^{-2}$ for the DC3TBDTC: PBN-13 blend, $1.51 \times 10^{-4} / 1.41 \times 10^{-4} \mathrm{~cm}^{-2} \mathrm{~V}^{-1} \mathrm{~s}^{-2}$ for the DR3TBDTC:PBN-13 blend and $1.45 \times 10^{-4} / 1.33 \times 10^{-4} \mathrm{~cm}^{-2}$ $\mathrm{V}^{-1} \mathrm{~s}^{-2}$ for the DI3TBDTC:PBN-13 blend, respectively. Among them, the more balanced hole and electron mobilities of the DR3TBDTC:PBN-13 blend should favor the FF and PCE.

In order to investigate the charge generation, collection and recombination behaviors of these blends, the photocurrent density $\left(J_{\mathrm{ph}}\right)$ versus the effective voltage $\left(V_{\text {eff }}\right)$ and the dependence of $J_{\mathrm{SC}}$ on the light density $(P)$ of the DC3TBDTC-, DR3TBDTC- and DI3TBDTC-based devices were measured. As shown in Supplementary Figure S7a, the $J_{\mathrm{ph}}$ increases as $V_{\text {eff }}$ rises, and $J_{\mathrm{ph}}$ reaches saturation at a $V_{\text {eff }}$ of $5 \mathrm{~V}$. The $J_{\mathrm{ph}, \mathrm{sc}} / J_{\mathrm{ph}, \mathrm{sat}}$ value $\left(J_{\mathrm{ph}, \mathrm{sc}}\right.$ is the $J_{\mathrm{ph}}$ under short-circuit condition, $J_{\mathrm{ph} \text {,sat }}$ is the

Table 2 Photovoltaic parameters of the OSCs based on DC3TBDTC:PBN-13, DR3TBDTC:PBN-13 and DI3TBDTC:PBN-13 blend films

\begin{tabular}{|c|c|c|c|c|c|c|c|c|c|}
\hline Donors & $V_{\mathrm{OC}}(\mathrm{V})$ & $J_{\mathrm{sC}}\left(\mathrm{mA} / \mathrm{cm}^{2}\right)$ & $\mathrm{FF}$ & PCE (\%) & $\Delta \mathrm{PL}_{\text {donor }}$ & $\mu_{\mathrm{h}}\left(10^{-4} \mathrm{~cm}^{2} \mathrm{~V}^{-1} \mathrm{~s}^{-1}\right)$ & $\mu_{\mathrm{e}}\left(10^{-4} \mathrm{~cm}^{2} \mathrm{~V}^{-1} \mathrm{~s}^{-1}\right)$ & $P_{\mathrm{c}}(\%)$ & $\alpha$ \\
\hline DC3TBDTC & 0.97 & 10.10 & 0.52 & 5.20 & 0.91 & 1.20 & 2.10 & 79.2 & 0.81 \\
\hline DR3TBDTC & 1.03 & 12.27 & 0.64 & 8.03 & 0.92 & 1.51 & 1.41 & 84.4 & 0.90 \\
\hline DI3TBDTC & 0.92 & 8.79 & 0.42 & 3.37 & 0.74 & 1.45 & 1.33 & 55.7 & 0.86 \\
\hline
\end{tabular}



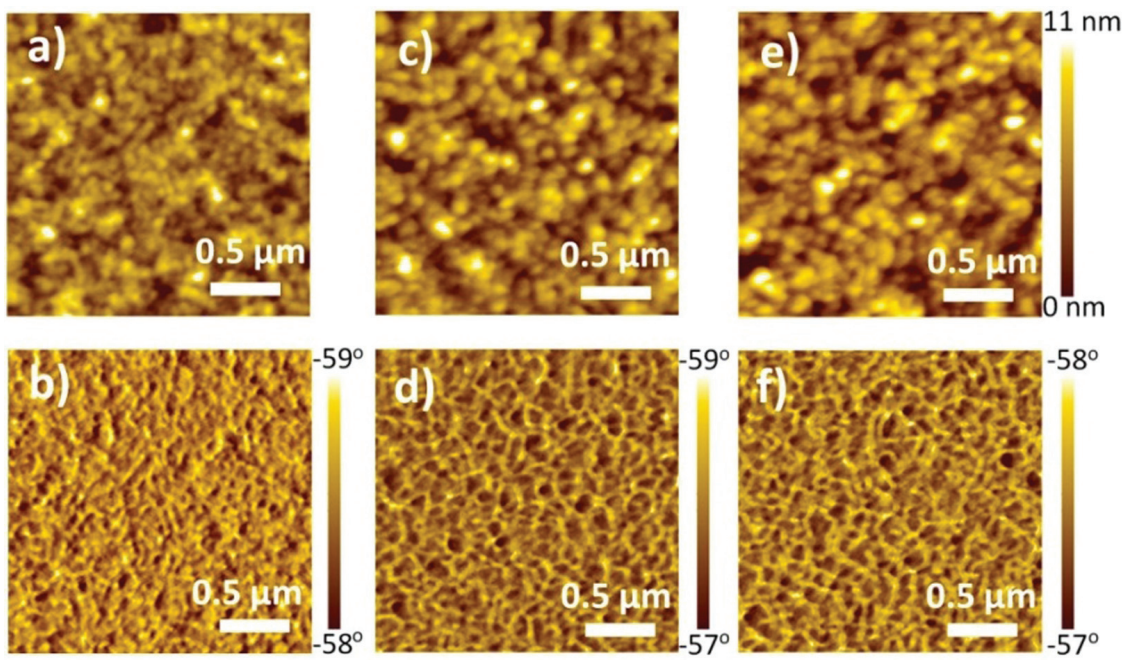

Figure 4 AFM height ( $a, c$ and e) and phase ( $b, d$ and $f$ ) images of the DC3TBDTC:PBN-13, DR3TBDTC:PBN-13 and DI3TBDTC:PBN-13 blend films.

$J_{\mathrm{ph}}$ at saturation) is used to evaluate the charge collection process in the OSC device. The $J_{\mathrm{ph}, \mathrm{SC}} / J_{\mathrm{ph}, \mathrm{sat}}$ values of DC3TBDTC-, DR3TBDTC- and DI3TBDTC-based devices are 79.2, 84.4 and 55.7\%, respectively. This indicates that the charge collection is efficient for the DR3TBDTC-based device. The relationship between $J_{\mathrm{sc}}$ and light intensity $(P)$ can be expressed as $J_{S C} \propto P^{\alpha}$ ( $\alpha$ is the power-law exponent). If all free charges can be swept out and collected by the electrode prior to recombination, $\alpha$ should be equal to 1 . While $\alpha<1$ means the existence of bimolecular recombination. As shown in Supplementary Figure S7b, the $\alpha$ values of DC3TBDTC-, DR3TBDTC- and DI3TBDTC-based devices are calculated to be $0.81,0.90$ and 0.86 , respectively, implying the suppressed bimolecular recombination of DR3TBDTC. The

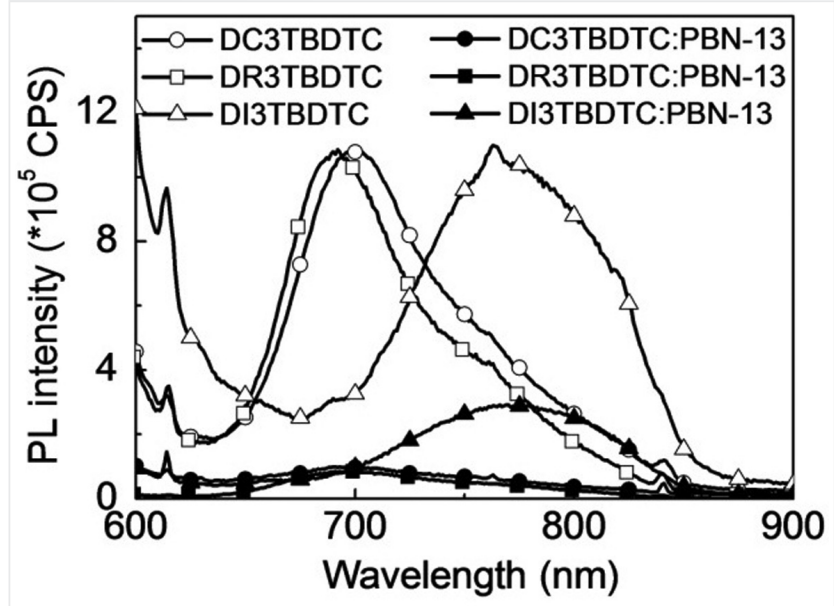

Figure 5 Photoluminescence spectra of pure DC3TBDTC, DR3TBDTC and DI3TBDTC films, and the DC3TBDTC:PBN-13, DR3TBDTC:PBN-13 and DI3TBDTC:PBN-13 blend films (excited at $560 \mathrm{~nm}$ ). efficient charge generation and collection, and low charge recombination behavior agree well with the high device performance of the DR3TBDTC-based device.

\section{Conclusions}

In conclusion, we have developed three small-molecule donors, DC3TBDTC, DR3TBDTC and DI3TBDTC, using the benzodithiophene unit bearing carbazolyl substituents as the core, terthiophene as the bridge units and methyl 2-cyanoacetate, 3-ethylrhodanine and $2 \mathrm{H}$-indene-1,3-dione as the terminal groups, respectively. All of the molecules show high crystallinity, high HOMO/LUMO energy levels and broad absorption bands spanning the visible region. The terminal groups of these molecules have little influence on HOMO energy levels but can greatly affect LUMO energy levels. DI3TBDTC with strong electron-withdrawing terminal groups shows the lowest LUMO energy level and thus the smallest bandgap. The OSC devices based on these smallmolecule donors exhibit good performance with PCEs of up to $8.03 \%$ for DR3TBDTC, which is among the highest values reported to date for $\mathrm{M}_{\mathrm{D}} / \mathrm{P}_{\mathrm{A}}$-type OSCs. These results indicate that adjustment of terminal groups of molecular donors has great influence on optoelectronic properties and provide important guidelines for the design of small-molecule donors for $\mathrm{M}_{\mathrm{D}} / \mathrm{P}_{\mathrm{A}}$-type OSCs.

\section{Experimental Procedure}

All chemicals and reagents were purchased from commercial sources and used as received. Chloroform was dried using calcium hydroxide. The small-molecule donor of 
DR3TBDTC was synthesized as the reported method in our laboratory. ${ }^{50}$

Synthesis of DC3TBDTC. Compound $(\mathbf{1})^{50}$ (0.10 g, 0.057 $\mathrm{mmol})$ and methyl 2-cyanoacetate $(0.057 \mathrm{~g}, 0.57 \mathrm{mmol})$ were dissolved in anhydrous $\mathrm{CHCl}_{3}(15 \mathrm{~mL})$, and then two drops of triethylamine were added to the mixture. Then, the mixture was stirred at room temperature for $14 \mathrm{~h}$. The reaction mixture was concentrated in vacuum. The residue was purified by silica gel column chromatography with $4: 1$ $(\mathrm{v} / \mathrm{v})$ chloroform-petroleum ether as an eluent and recrystallized in methyl alcohol/chloroform to afford DC3TBDTC as a brown solid (0.095 g, 87\%). ${ }^{1} \mathrm{H}$ NMR (400 MHz, $\left.\mathrm{CDCl}_{3}\right)$ : $\delta(\mathrm{ppm}) 8.49(\mathrm{~s}, 2 \mathrm{H}), 8.20-8.18(\mathrm{~d}, J=8.1 \mathrm{~Hz}, 4 \mathrm{H})$, 7.85-7.83 (d, $J=8.4 \mathrm{~Hz}, 2 \mathrm{H}), 7.76-7.63(\mathrm{~d}, J=8.5 \mathrm{~Hz}, 2 \mathrm{H})$, 7.58 (s, $2 \mathrm{H}), 7.55-7.48$ (m, $4 \mathrm{H}), 7.45$ (s, $2 \mathrm{H}), 7.31-7.24$ (m, $4 \mathrm{H}), 7.06(\mathrm{~s}, 4 \mathrm{H}), 4.30-4.29(\mathrm{~d}, J=7.0 \mathrm{~Hz}, 4 \mathrm{H}), 3.90(\mathrm{~s}, 6$ $\mathrm{H}), 2.81-2.77(\mathrm{t}, J=7.6 \mathrm{~Hz}, 4 \mathrm{H}), 2.73-2.70(\mathrm{t}, J=7.6 \mathrm{~Hz}$, $4 \mathrm{H}), 2.32-2.20(\mathrm{~m}, 2 \mathrm{H}), 1.70-1.58(\mathrm{~m}, 8 \mathrm{H}), 1.49-1.14$ $(\mathrm{m}, 56 \mathrm{H}), 1.04-1.00(\mathrm{t}, J=7.2 \mathrm{~Hz}, 6 \mathrm{H}), \quad 0.95-0.91$ $(\mathrm{t}, J=7.2 \mathrm{~Hz}, 6 \mathrm{H}), \quad 0.86-0.81(\mathrm{~m}, 12 \mathrm{H}) .{ }^{13} \mathrm{C}$ NMR $\left(125 \mathrm{MHz}, \mathrm{CDCl}_{3}\right): \delta(\mathrm{ppm}) 163.65,146.28,141.95$, $141.62,141.58,141.24,140.94,140.89,140.83,140.60$, $138.76,138.60,137.59,137.16,136.13,134.11,132.83$, $130.63,129.93,129.55,128.29,128.22,126.93,126.08$, $123.33,122.81,120.60,119.30,119.12,116.05,109.50$, 109.29, 97.12, 53.16, 48.04, 38.21, 32.01, 31.84, 31.82, 31.73, $30.38,30.17,29.69,29.66,29.58,29.39,29.35,29.33,29.22$, 29.20, 28.87, 26.62, 23.14, 22.65, 22.63, 14.12, 14.08, -0.01. Elemental analyses calculated (\%) for $\mathrm{C}_{116} \mathrm{H}_{134} \mathrm{~N}_{4} \mathrm{O}_{4} \mathrm{~S}_{8}$ (DC3TBDTC): C, 73.14; H, 7.09; N, 2.94. Found: C, 73.25; H, 7.02; N, 2.89.

Synthesis of DI3TBDTC. Compound 1 (0.12 g, 0.069 $\mathrm{mmol})$ and $2 \mathrm{H}$-indene-1,3-dione $(0.10 \mathrm{~g}, 0.69 \mathrm{mmol})$ were dissolved in anhydrous $\mathrm{CHCl}_{3}(30 \mathrm{~mL})$, and then three drops of triethylamine were added to the mixture. Then, the mixture was stirred at room temperature for $12 \mathrm{~h}$. The reaction mixture was concentrated in vacuum. The residue was purified by silica gel column chromatography with chloroform as an eluent and recrystallized in methyl alcohol/chloroform to afford DI3TBDTC as a brown solid (0.11 g, 82\%). ${ }^{1} \mathrm{H}$ NMR (400 MHz, $\mathrm{CDCl}_{3}$ ): $\delta$ (ppm) 8.50 (s, $2 \mathrm{H}), 8.21-8.19$ (d, $J=7.7 \mathrm{~Hz}, 2 \mathrm{H}), 7.95-7.92(\mathrm{~m}, 4 \mathrm{H})$, 7.86-7.83 (m, $4 \mathrm{H}), 7.81(\mathrm{~s}, 2 \mathrm{H}), 7.77-7.73(\mathrm{~m}, 4 \mathrm{H})$, 7.65-7.63 (d, $J=8.4 \mathrm{~Hz}, 2 \mathrm{H}), 7.56-7.45(\mathrm{~m}, 6 \mathrm{H}), 7.34-7.33$ $(\mathrm{d}, J=4.0 \mathrm{~Hz}, 2 \mathrm{H}), 7.31-7.28(\mathrm{t}, J=7.6 \mathrm{~Hz}, 2 \mathrm{H}), 7.09-7.05$ $(\mathrm{m}, 4 \mathrm{H}), \quad 4.30-4.28(\mathrm{~d}, J=7.0 \mathrm{~Hz}, 4 \mathrm{H}), \quad 2.84-2.80$ $(\mathrm{t}, J=7.6 \mathrm{~Hz}, 4 \mathrm{H}), 2.75-2.71(\mathrm{t}, J=7.6 \mathrm{~Hz}, 4 \mathrm{H})$, 2.33-2.21 (m, $2 \mathrm{H}), 1.72-1.57(\mathrm{~m}, 8 \mathrm{H}), \quad 1.47-1.15$ $(\mathrm{m}, 56 \mathrm{H}), \quad 1.04-1.00(\mathrm{t}, J=4.8 \mathrm{~Hz}, 6 \mathrm{H}), \quad 0.95-0.92$ $(\mathrm{t}, J=6.8 \mathrm{~Hz}, 6 \mathrm{H}), \quad 0.86-0.81(\mathrm{~m}, 12 \mathrm{H}),{ }^{13} \mathrm{C}$ NMR $\left(100 \mathrm{MHz}, \mathrm{CDCl}_{3}\right): \delta(\mathrm{ppm})$ 190.37, 189.63, 145.24, $144.90,142.01,141.54,141.05,140.78,140.73,140.46$, $138.68,138.52,137.53,137.11,136.03,135.56,134.88$, $134.80,134.65,134.58,130.50,130.16,129.54,128.18$,
$128.09,126.95,126.19,126.02,123.74,123.30,122.88$, $122.85,122.72,121.19,120.64,119.25,119.09,109.45$, $109.24,48.01,38.20,32.01,31.85,31.81,31.73,30.36,30.09$, $29.75,29.70,29.64,29.54,29.43,29.41,29.37,29.25,28.87$, $26.62,23.15,22.64,14.14,14.09,14.02,-0.01$. Elemental analyses calculated (\%) for $\mathrm{C}_{126} \mathrm{H}_{136} \mathrm{~N}_{2} \mathrm{O}_{4} \mathrm{~S}_{8}$ (DI3TBDTC): C, 75.71; H, 6.86; N, 1.40. Found: C, 75.58; H, 6.93; N, 1.46.

\section{Funding Information}

The authors are grateful for the financial supports by the Natural Science Foundation of China (No. 21625403, 21875244, 21875241, 51603203, and 21761132020).

\section{Supporting Information}

Supporting information for this article is available online at: https://doi.org/10.1055/s-0039-3401017.

\section{References}

(1) Zhang, G.; Zhao, J.; Chow, P. C. Y.; Jiang, K.; Zhang, J.; Zhu, Z.; Zhang, J.; Huang, F.; Yan, H. Chem. Rev. 2018, 118, 3447.

(2) Collins, S. D.; Ran, N. A.; Heiber, M. C.; Nguyen, T.-Q. Adv. Energy. Mater. 2017, 7, 1602242.

(3) Genene, Z.; Mammo, W.; Wang, E.; Andersson, M. R. Adv. Mater. 2019, 31, 1807275.

(4) Yao, H.; Ye, L.; Zhang, H.; Li, S.; Zhang, S.; Hou, J. Chem. Rev. 2016, 116, 7397.

(5) Fan, Q.; Su, W.; Wang, Y.; Guo, B.; Jiang, Y.; Guo, X.; Liu, F.; Russell, T. P.; Zhang, M.; Li, Y. Sci. China Chem. 2018, 61, 531.

(6) Lin, Y.; Wang, J.; Zhang, Z.-G.; Bai, H.; Li, Y.; Zhu, D.; Zhan, X. Adv. Mater. 2015, 27, 1170.

(7) Hou, J.; Inganäs, O.; Friend, R. H.; Gao, F. Nat. Mater. 2018, 17, 119.

(8) Meng, L.; Zhang, Y.; Wan, X.; Li, C.; Zhang, X.; Wang, Y.; Ke, X.; Xiao, Z.; Ding, L.; Xia, R.; Yip, H.-L.; Cao, Y.; Chen, Y. Science 2018, 361, 1094.

(9) Yuan, J.; Zhang, Y.; Zhou, L.; Zhang, G.; Yip, H.-L.; Lau, T.-K.; Lu, X.; Zhu, C.; Peng, H.; Johnson, P. A.; Leclerc, M.; Cao, Y.; Ulanski, J.; Li, Y.; Zou, Y. Joule 2019, 3, 1140.

(10) Fan, B.; Zhang, D.; Li, M.; Zhong, W.; Zeng, Z.; Ying, L.; Huang, F.; Cao, Y. Sci. China Chem. 2019, 62, 746.

(11) Xu, X.; Feng, K.; Bi, Z.; Ma, W.; Zhang, G.; Peng, Q. Adv. Mater. 2019, 31, 1901872.

(12) Ni, W.; Wan, X.; Li, M.; Wang, Y.; Chen, Y. Chem. Commun. 2015, $51,4936$.

(13) Sun, K.; Xiao, Z.; Lu, S.; Zajaczkowski, W.; Pisula, W.; Hanssen, E.; White, J. M.; Williamson, R. M.; Subbiah, J.; Ouyang, J.; Holmes, A. B.; Wong, W. W. H. Jones, D. J. Nat. Commun. 2015, 6, 6013.

(14) Wang, J.-L.; Liu, K.-K.; Yan, J.; Wu, Z.; Liu, F.; Xiao, F.; Chang, Z.-F.; Wu, H. B.; Cao, Y.; Russell, T. P. J. Am. Chem. Soc. 2016, 138, 7687.

(15) Huang, Y.; Wen, W.; Mukherjee, S.; Ade, H.; Kramer, E. J.; Bazan, G. C. Adv. Mater. 2014, 26, 4168.

(16) Wang, J.; Xiao, M.; Chen, W.; Qiu, M.; Du, Z.; Zhu, W.; Wen, S.; Wang, N.; Yang, R. Macromolecules 2014, 47, 7823.

(17) Yao, K.; Chen, L.; Chen, X.; Chen, Y. Chem. Mater. 2013, $25,897$. 
(18) Yuan, L.; Zhao, Y.; Zhang, J.; Zhang, Y.; Zhu, L.; Lu, K.; Yan, W.; Wei, Z. Adv. Mater. 2015, 27, 4229.

(19) Fan, B.; Ying, L.; Wang, Z.; He, B.; Jiang, X.-F.; Huang, F.; Cao, Y. Energy Environ. Sci. 2017, 10, 1243.

(20) Yang, Y.; Qiu, B.; Chen, S.; Zhou, Q.; Peng, Y.; Zhang, Z.-G.; Yao, J.; Luo, Z.; Chen, X.; Xue, L.; Feng, L.; Yang, C.; Li, Y.J. Mater. Chem. A 2018, 6, 9613

(21) Jung, J. W.; Russell, T. P.; Jo, W. H. Chem. Mater. 2015, 27, 4865.

(22) Long, X.; Ding, Z.; Dou, C.; Zhang, J.; Liu, J.; Wang, L. Adv. Mater. 2016, 28, 6504.

(23) Jeong, M.; Chen, S.; Lee, S. M.; Wang, Z.; Yang, Y.; Zhang, Z.-G.; Zhang, C.; Xiao, M.; Li, Y.; Yang, C. Adv. Energy Mater. 2018, 8, 1702166.

(24) Liu, Y.; Zhang, Z.; Feng, S.; Li, M.; Wu, L.; Hou, R.; Xu, X.; Chen, X.; Bo, Z. J. Am. Chem. Soc. 2017, 139, 3356.

(25) Wu, H.; Yue, Q.; Zhou, Z.; Chen, S.; Zhang, D.; Xu, S.; Zhou, H.; Yang, C.; Fan, H.; Zhu, X. J. Mater. Chem. A 2019, 7, 15944.

(26) Bin, H.; Yang, Y.; Zhang, Z.-G.; Ye, L.; Ghasemi, M.; Chen, S.; Zhang, Y.; Zhang, C.; Sun, C.; Xue, L.; Yang, C.; Ade, H.; Li, Y.J. Am. Chem. Soc. 2017, 139, 5085.

(27) Feng, G.; Li, J.; He, Y.; Zheng, W.; Wang, J.; Li, C.; Tang, Z.; Osvet, A.; Li, N.; Brabec, C. J.; Yi, Y.; Yan, H.; Li, W. Joule 2019, 3, 1765.

(28) Zhao, R.; Dou, C.; Liu, J.; Wang, L. Chin. J. Polym. Sci. 2017, 35, 198.

(29) Miao, J.; Meng, B.; Liu, J.; Wang, L. Chem. Commun. 2018, 54, 303.

(30) Wu, X.-F.; Fu, W.-F.; Xu, Z.; Shi, M.; Liu, F.; Chen, H.-Z.; Wan, J.-H.; Russell, T. P. Adv. Funct. Mater. 2015, 25, 5954.

(31) Kan, B.; Feng, H.; Yao, H.; Chang, M.; Wan, X.; Li, C.; Hou, J.; Chen, Y. Sci. China Chem. 2018, 61, 1307.

(32) Dou, C.; Long, X.; Ding, Z.; Xie, Z.; Liu, J.; Wang, L. Angew. Chem. Int. Ed. 2016, 55, 1436.

(33) Dou, C.; Ding, Z.; Zhang, Z.; Xie, Z.; Liu, J.; Wang, L. Angew. Chem. Int. Ed. 2015, 127, 3719.

(34) Dou, C.; Liu, J.; Wang, L. Sci. China Chem. 2017, 60, 450.

(35) Müller, C. Chem. Mater. 2015, 27, 2740.

(36) Zhang, Z.; Ding, Z.; Miao, J.; Xin, J.; Ma, W.; Dou, C.; Liu, J.; Wang, L. J. Mater. Chem. C 2019, 7, 10521.

(37) Oh, S.; Badgujar, S.; Kim, D. H.; Lee, W.-E.; Khan, N.; Jahandar, M.; Rasool, S.; Song, C. E.; Lee, H. K.; Shin, W. S.; Lee, J.-C.; Moon, S.-J.; Lee, S. K. J. Mater. Chem. A 2017, 5, 15923.
(38) Kim, Y. J.; Chung, D. S.; Park, C. E. Nano. Energy 2015, 15, 343.

(39) Tang, Z.; Liu, B.; Melianas, A.; Bergqvist, J.; Trees, W.; Bao, Q.; Qian, D.; Inganãs, O.; Zhang, F. Adv. Mater. 2015, 27, 1900.

(40) Geng, Y.; Xiao, B.; Izawa, S.; Huang, J.; Tajima, K.; Zeng, Q.; Zhou, E. J. Mater. Chem. A 2015, 3, 22325.

(41) Yuan, J.; Ma, W. Org. Electron. 2016, 39, 279.

(42) Zhang, Z.; Ding, Z.; Jones, D. J.; Wong, W. W. H.; Kan, B.; Bi, Z.; Wan, X.; Ma, W.; Chen, Y.; Long, X.; Dou, C.; Liu, J.; Wang, L. Sci. China Chem. 2018, 61, 1025.

(43) Zhang, Z.; Ding, Z.; Long, X.; Dou, C.; Liu, J.; Wang, L. J. Mater. Chem. C 2017, 5, 6812 .

(44) Zhou, J.; Zuo, Y.; Wan, X.; Long, G.; Zhang, Q.; Ni, W.; Liu, Y.; Li, Z.; He, G.; Li, C.; Kan, B.; Li, M.; Chen, Y. J. Am. Chem. Soc. 2013, 135 , 8484.

(45) Wan, J.; Xu, X.; Zhang, G.; Li, Y.; Feng, K.; Peng, Q. Energy Environ. Sci. 2017, 10, 1739.

(46) Cheng, P.; Zhao, X.; Zhou, W.; Hou, J.; Li, Y.; Zhan, X. Org. Electron. 2014, 15, 2270.

(47) Li, Z.; Lin, J. DA.; Phan, H.; Sharenko, A.; Proctor, C. M.; Zalar, P.; Chen, Z.; Facchetti, A.; Nguyen, T.-Q. Adv. Funct. Mater. 2014, 24 , 6989.

(48) Wang, Y.; Zhao, X.; Zhan, X. J. Mater. Chem. C 2015, 3, 447.

(49) Miao, J.; Xu, H.; Meng, B.; Liu, J.; Wang, L. Chin. J. Chem. 2018, 36, 411.

(50) Zhang, Z.; Miao, J.; Ding, Z.; Kan, B.; Lin, B.; Wan, X.; Ma, W.; Chen, Y.; Long, X.; Dou, C.; Zhang, J.; Liu, J.; Wang, L. Nat. Commun. 2019, 10, 3271.

(51) He, G.; Li, Z.; Wan, X.; Liu, Y.; Zhou, J.; Long, G.; Zhang, M.; Chen, Y. J. Mater. Chem. 2012, 22, 9173.

(52) Intemann, J. J.; Yao, K.; Ding, F.; Xu, Y.; Xin, X.; Li, X.; Jen, A. K.-Y. Adv. Funct. Mater. 2015, 25, 4889.

(53) Long, G.; Wan, X.; Kan, B.; Liu, Y.; He, G.; Li, Z.; Zhang, Y.; Zhang, Y.; Zhang, Q.; Zhang, M.; Chen, Y. Adv. Energy Mater. 2013, 3, 639.

(54) He, G.; Li, Z.; Wan, X.; Zhou, J.; Long, G.; Zhang, S.; Zhang, M.; Chen, Y. J. Mater. Chem. A 2013, 1, 1801.

(55) Yuan, L.; Lu, K.; Xia, B.; Zhang, J.; Wang, Z.; Wang, Z.; Deng, D.; Fang, J.; Zhu, L.; Wei, Z. Adv. Mater. 2016, 28, 5980. 